\title{
Time Is Kidney: Relation between Pain-to-Balloon Time and Acute Kidney Injury among ST Segment Elevation Patients Undergoing Primary Percutaneous Intervention
}

\author{
David Zahler Keren Lee-Rozenfeld Tamar Itach Lior Lupu Shmuel Banai \\ Yacov Shacham \\ Department of Cardiology, Tel-Aviv Sourasky Medical Center Affiliated to the Sackler Faculty of Medicine, \\ Tel-Aviv University, Tel-Aviv, Israel
}

\section{Keywords}

Time to reperfusion $\cdot$ Ischemia $\cdot$ Acute kidney injury $\cdot$ Acute myocardial infarction

\begin{abstract}
Background: Among ST segment elevation myocardial infarction (STEMI), early hemodynamic changes may result in acute kidney injury (AKI) even prior to primary percutaneous coronary intervention ( $\mathrm{PCl}$ ); however, no information to date is present regarding the association between pain-to-balloon time (PBT) and AKI. We evaluated whether PBT predicts the risk of AKI among STEMI patients undergoing primary $\mathrm{PCl}$. Methods: Medical records of 2,343 STEMI patients undergoing primary $\mathrm{PCl}$ were reviewed. Patients were stratified by PBT into 3 groups: $\leq 120,121-360$, and $>360$ min. Patients' records were assessed for the occurrence of AKI (defined by the KDIGO criteria as serum creatinine ( $\mathrm{s} C r$ ) elevation $\geq 0.3$ $\mathrm{mg} / \mathrm{dL}$ within $72 \mathrm{~h}$ after admission). Results: Mean age was $61 \pm 13$ years, and 1,919 (82\%) were male. Patients having longer PBT had more AKI complicating the course of STEMI ( $7 \%$ vs. $8 \%$ vs. $13 \%, p<0.001$ ) and had significantly higher sCr changes throughout hospitalization $(0.08 \mathrm{mg} / \mathrm{dL}$ vs. 0.11 $\mathrm{mg} / \mathrm{dL}$ vs. $0.17 \mathrm{mg} / \mathrm{dL} p<0.001)$. In a multivariable logistic
\end{abstract}

Karger@karger.com www.karger.com/crm

Karger ${ }^{\prime \prime} \div$

GOPEN ACCESS
C 2022 The Author(s).

Published by S. Karger AG, Basel

This is an Open Access article licensed under the Creative Commons Attribution-NonCommercial-4.0 International License (CC BY-NC) (http://www.karger.com/Services/OpenAccessLicense), applicable to the online version of the article only. Usage and distribution for commercial purposes requires written permission. regression model, each 1-h increase in PBT was independently associated with a $2.2 \%$ increase in risk for AKI (odds ratio $1.022,95 \%$ confidence interval: $1.01-1.04, p=0.02$ ). Conclusion: Longer PBT may be an independent marker for the development of AKI in STEMI patients undergoing primary.

(c) 2022 The Author(s).

Published by S. Karger AG, Basel

\section{Background}

While contrast nephropathy is considered the most important mechanism for worsening of renal function among ST segment elevation myocardial infarction (STE$\mathrm{MI})$ patients treated by primary percutaneous coronary intervention (PCI) [1-3], recent data suggested the role of other important factors $[4,5]$. Time to reperfusion is a powerful prognostic marker in STEMI patients $[6,7]$, and a major effort is invested in minimizing total ischemic

All the authors take responsibility for all aspects of the reliability and freedom from bias of the data presented and their discussed interpretation. 
duration in order to improve survival following STEMI [8].

The sudden myocardial insult in STEMI with acute reduction in left-ventricle function often results in an acute reduction in the cardiac output [5]. This early hemodynamic deterioration may, in theory, lead to reduced renal perfusion and consequently to acute kidney injury (AKI). Renal hypoperfusion primarily affects the function and structure of tubular epithelial cells, which, in severe cases, is characterized by epithelial cell ischemia and necrosis [9-11]. These alterations can result in irreversible loss or delayed restoration of renal function and may also increase susceptibility to contrast-induced AKI in patients undergoing primary PCI [12]. We hypothesized that among STEMI patients, longer pain-to-balloon time (PBT) prolongs decreased renal perfusion, thus increasing the risk for AKI development.

\section{Methods}

A retrospective, single center observational study was performed at the Tel-Aviv Sourasky Medical Center, a tertiary referral hospital with a 24/7 primary PCI service.

\section{Study Population}

Included were 2,586 patients, admitted between 2007 and 2019 with the diagnosis of acute STEMI subsequently treated with primary PCI. Patients transferred from other hospitals $(n=32)$ were excluded. Patients in whom no documentation of the PBT interval or renal function parameters was found in medical records were excluded as well $(n=211)$. The final study population included 2,343 STEMI patients.

\section{Clinical Definitions}

Diagnosis of STEMI was established in accordance to published guidelines including a typical chest pain history, diagnostic electrocardiographic changes, and serial elevation of cardiac biomarkers [13]. Primary PCI was performed in patients with symptoms $\leq 12 \mathrm{~h}$ in duration as well as in patients with symptoms lasting $12-24 \mathrm{~h}$ if pain consisted at the time of admission. Pain-to-door time (PDT) was defined as time from the symptom onset (usually chest pain or discomfort) to hospital admission (either to the emergency room or directly to the catheterization laboratory) as documented in the patient's medical records. Door-to-balloon time (DBT) was defined as the time interval between a patient's arrival at the hospital and the first balloon inflation or device deployment in the culprit artery as taken from the computerized patient file. PBT was defined as the sum of PDT and DBT times.

All patients underwent a screening echocardiographic examination within 3 days of admission to assess left ventricular (LV) ejection fraction. For the purpose of evaluating differences in patient characteristics and outcomes, we stratified patients into 3 groups based on PTB: $\leq 120$ and 121-360 and $>360$ min. Baseline demographics, cardiovascular history, clinical risk factors, laboratory results, coronary findings during PCI, and echocardiographic measurements were all retrieved from the hospital electronic medical records.

\section{Laboratory}

The initial serum creatinine ( $\mathrm{sCr}$ ) level was determined upon hospital admission (prior to primary PCI). Follow-up levels were evaluated at least once daily during the postinterventional stay at the cardiac intensive care unit or the intermediate care step-down unit. The estimated glomerular filtration rate was calculated using the Chronic Kidney Disease Epidemiology Collaboration equation [14]. Chronic kidney disease (CKD) was defined as an admission estimated glomerular filtration rate of $\leq 60 \mathrm{~mL} / \mathrm{min} / 1.73 \mathrm{~m}^{2}$ [14], based on $\mathrm{sCr}$ at presentation. AKI occurrence was determined based on the KDIGO criteria and defined as an increase in $\mathrm{sCr} \geq 0.3$ $\mathrm{mg} / \mathrm{dL}$ within $48 \mathrm{~h}$ of admission [15].

In a subgroup of 224 patients, serum neutrophil gelatinase-associated lipocalin (NGAL) levels from venous blood were collected $24 \mathrm{~h}$ following admission to the cardiac intensive care unit. Samples were centrifuged within 10 min using a cooled centrifuge, and plasma and serum were stored at $-20^{\circ} \mathrm{C}$. NGAL levels were analyzed using NGAL rapid turbidimetric immunoassay (Bioporto Diagnostics, Copenhagen, Denmark).

\section{Statistical Methods}

Continuous variables were presented as mean and standard deviation and compared with the one-way ANOVA. Categorical variables are presented as number and percentages, and $p$ values were calculated with the $\chi^{2}$ test or Fisher's exact test when appropriate. Potential independent predictors of AKI were assessed using multivariate logistic regression models adjusted for all baseline variables found to be significant in univariate analysis. A twotailed $p$ value of $<0.05$ was considered significant for all analyses. All analyses were performed with the SPSS software (SPSS Inc., Chicago, IL, USA).

\section{Results}

Study population included 2,343 STEMI patients (age $61 \pm 13,82 \%$ men); of these, $852(36 \%)$ had PBT $\leq 120$ min, 925 (40\%) had PBT of 121-360 min, and 566 (24\%) had PBT $>360 \mathrm{~min}$. Table 1 presents the baseline characteristics of patients according to the $3 \mathrm{PBT}$ groups. $\mathrm{Pa}$ tients with longer PBT were older, more likely to be female, and had more comorbidities. There was a graded increase in both PDT and DBT time within the 3 groups; however, mean DBTs were still $<90$ min for all groups.

Table 2 compares the occurrence of AKI and $\mathrm{sCr}$ changes within the 3 groups. Prolonged PBT was associated with a higher incidence of AKI complicating the course of STEMI (7\% vs. $7.7 \%$ vs. $13.1 \%, p<0.001$, Fig. 1 ) and significantly higher $\mathrm{sCr}$ changes throughout hospitalization $(p<0.001)$. There was no significant difference in the presence of CKD at presentation and the amount of contrast volume used during PCI. In a subgroup anal- 
Table 1. Baseline characteristics of 2,343 STEMI patients stratified by PBTs

\begin{tabular}{|c|c|c|c|c|}
\hline & $\begin{array}{l}\mathrm{PBT}<120 \mathrm{~min} \\
(n=852)\end{array}$ & $\begin{array}{l}\text { PBT } 120-360 \mathrm{~min} \\
(n=925)\end{array}$ & $\begin{array}{l}\text { PBT }>360 \mathrm{~min} \\
(n=566)\end{array}$ & $p$ value \\
\hline Age, mean $\pm S D$, years & $59 \pm 12$ & $62 \pm 13$ & $63 \pm 14$ & $<0.001$ \\
\hline Gender (men), $n(\%)$ & $735(86)$ & $740(80)$ & $442(78)$ & $<0.001$ \\
\hline Hypertension, $n$ (\%) & $329(39)$ & $416(45)$ & $278(49)$ & $<0.001$ \\
\hline Diabetes mellitus, $n(\%)$ & $163(19)$ & $206(22)$ & $163(29)$ & $<0.001$ \\
\hline Family history of CAD, $n(\%)$ & $181(21)$ & $219(24)$ & $99(18)$ & 0.02 \\
\hline Past myocardial infarction, $n(\%)$ & $125(15)$ & $115(12)$ & $63(11)$ & 0.13 \\
\hline Smoking history, $n$ (\%) & $436(51)$ & $482(52)$ & $272(48)$ & 0.31 \\
\hline Hyperlipidemia, $n(\%)$ & $405(48)$ & $441(48)$ & $280(49)$ & 0.73 \\
\hline \multicolumn{5}{|l|}{ Coronary artery disease severity } \\
\hline One vessel disease, $n(\%)$ & $394(46)$ & $389(42)$ & $228(40)$ & \\
\hline Two vessel disease, $n(\%)$ & $257(30)$ & $286(31)$ & $164(29)$ & 0.04 \\
\hline Three vessel disease, $n(\%)$ & $202(24)$ & $251(27)$ & $174(31)$ & \\
\hline $\mathrm{PDT}$, mean $\pm \mathrm{SD}, \min$ & $57 \pm 17$ & $153 \pm 62$ & $954 \pm 431$ & $<0.001$ \\
\hline $\mathrm{DBT}$, mean $\pm \mathrm{SD}, \min$ & $36 \pm 14$ & $49 \pm 23$ & $54 \pm 27$ & $<0.001$ \\
\hline LV ejection fraction, mean $\pm S D$ & $48 \pm 8$ & $47 \pm 8$ & $46 \pm 8$ & $<0.001$ \\
\hline
\end{tabular}

CAD, coronary artery disease.

Table 2. Renal characteristics at presentation and outcomes according time to reperfusion

\begin{tabular}{|c|c|c|c|c|}
\hline & $\begin{array}{l}\mathrm{PBT} \leq 120 \mathrm{~min} \\
(n=852)\end{array}$ & $\begin{array}{l}\text { PBT } 121-360 \mathrm{~min} \\
(n=925)\end{array}$ & $\begin{array}{l}\mathrm{PBT}>360 \mathrm{~min} \\
(n=566)\end{array}$ & $p$ value \\
\hline eGFR at presentation, mean $\pm \mathrm{SD}, \mathrm{mL} / \mathrm{min} / 1.73^{2}$ & $75 \pm 23$ & $77 \pm 23$ & $74 \pm 24$ & 0.08 \\
\hline CKD, $* n(\%)$ & $189(22)$ & $210(23)$ & $149(26)$ & 0.16 \\
\hline $\mathrm{AKI}, n(\%)$ & $60(7.0)$ & $71(7.7)$ & $74(13.1)$ & $<0.001$ \\
\hline $\mathrm{sCr}$ change, mean $\pm \mathrm{SD}, \mathrm{mg} / \mathrm{dL}$ & $0.08 \pm 0.19$ & $0.11 \pm 0.32$ & $0.17 \pm 0.52$ & $<0.001$ \\
\hline Peak sCr, mean $\pm \mathrm{SD}, \mathrm{mg} / \mathrm{dL}$ & $1.19 \pm 0.38$ & $1.19 \pm 0.45$ & $1.29 \pm 0.78$ & 0.009 \\
\hline NGAL levels (mean $\pm \mathrm{SD})^{+}, \mathrm{ng} / \mathrm{mL}$ & $87 \pm 20$ & $104 \pm 32$ & $156 \pm 42$ & $<0.001$ \\
\hline Contrast material volume $(\text { mean } \pm \mathrm{SD})^{++}, \mathrm{mL}$ & $148 \pm 45$ & $143 \pm 45$ & $144 \pm 49$ & 0.64 \\
\hline
\end{tabular}

$\mathrm{SD}$, standard deviation; eGFR, estimated glomerular filtration rate, $\mathrm{s} C r$, serum creatinine. * CKD was defined using sCr at presentation. ${ }^{+}$NGAL levels were available in 224 patients. ${ }^{++}$Contrast volume was available for 406 patients.

ysis of 224 patients, serum NGAL levels also demonstrated a graded elevation with increased PTB time $(p<0.001)$.

As presented in Table 3, in a multivariate binary logistic regression model for the prediction of AKI, each 1-h increase in PBT was independently associated with an average $2.2 \%$ increase in risk for AKI occurrence (odds ratio $1.02,95 \%$ confidence interval: $1.01-1.04, p=0.02$, model 1). In a second model, PBT $>360$ min turned out to be a strong an independent predictor for AKI occurrence (odds ratio 1.6, 95\% confidence interval: 1.1-2.2, $p=$ 0.006 , model 2). Other factors independently associated with AKI included age $>60$ years, CKD, hypertension, and $\mathrm{LV}$ ejection fraction $\leq 45 \%$.

Time to Reperfusion and Acute Kidney Injury

\section{Discussion}

To all our knowledge, this is the first study assessing the relation between total ischemic time until reperfusion and AKI among STEMI patients. The main finding of the current study is that longer PBT is independently associated with the development of AKI in this population.

The latest era has seen a reduction in ischemic time by successfully focusing on DBT as a major objective for quality assessment [16], with the majority of patients nowadays treated within the relatively short recommended time frame once arriving at hospital doors $[17,18]$. The sudden myocardial insult in STEMI often results in an 


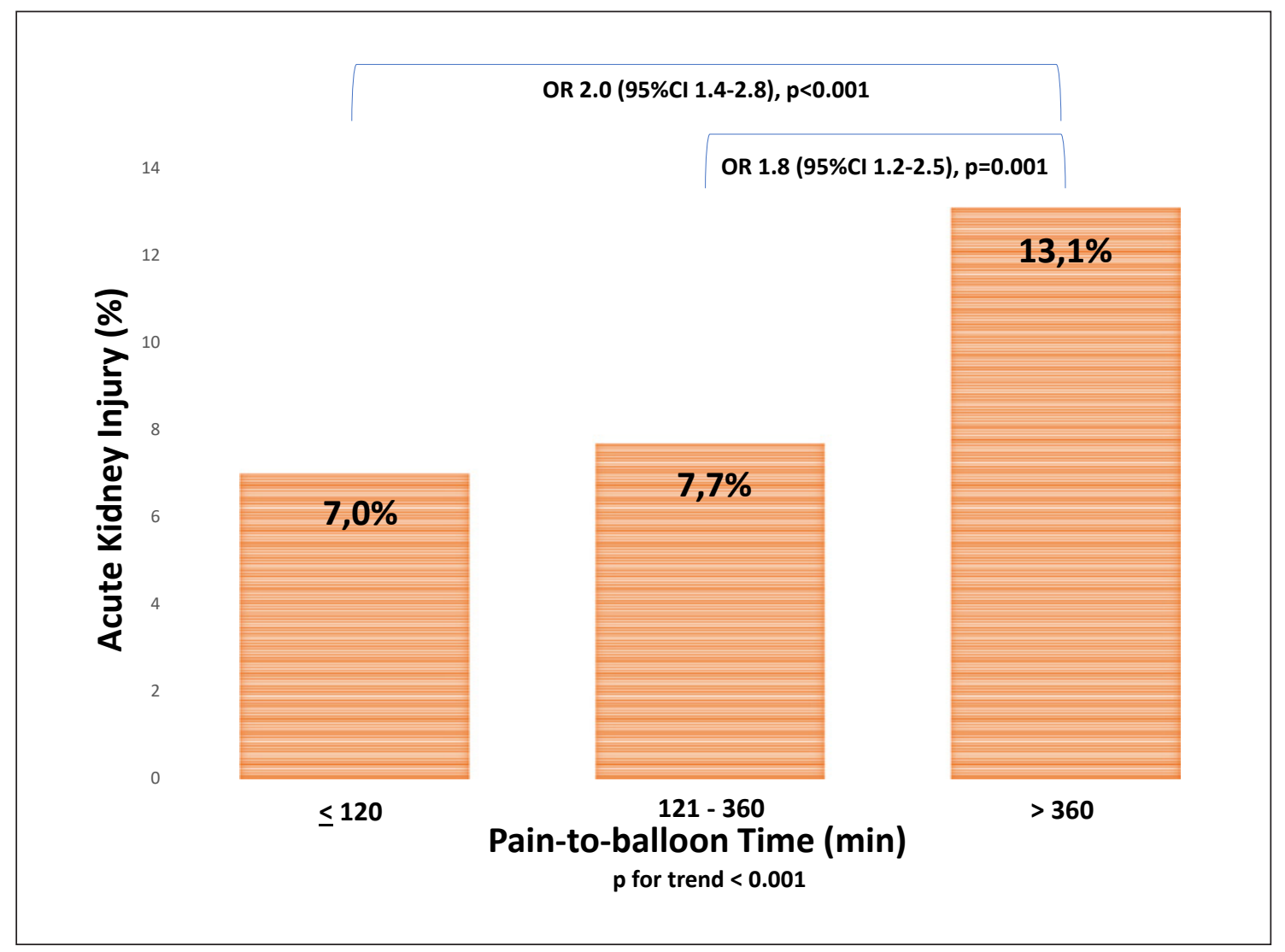

Fig. 1. Frequency of AKI among 2,343 STEMI patients undergoing primary percutaneous intervention, according to PBT $(p<0.001)$. OR presented in the figure represents the additional AKI risk for the third group (PBT $>360 \mathrm{~min}$ ) as compared to the first (PBT $\leq 120 \mathrm{~min}$, OR $2.0, p<0.001$ ) and the second (PBT 121-360 min, OR $1.8, p=0.001$ ) groups separately. $\mathrm{OR}$, odds ratio.

Table 3. Univariate and multivariate binary logistic regression analysis for AKI

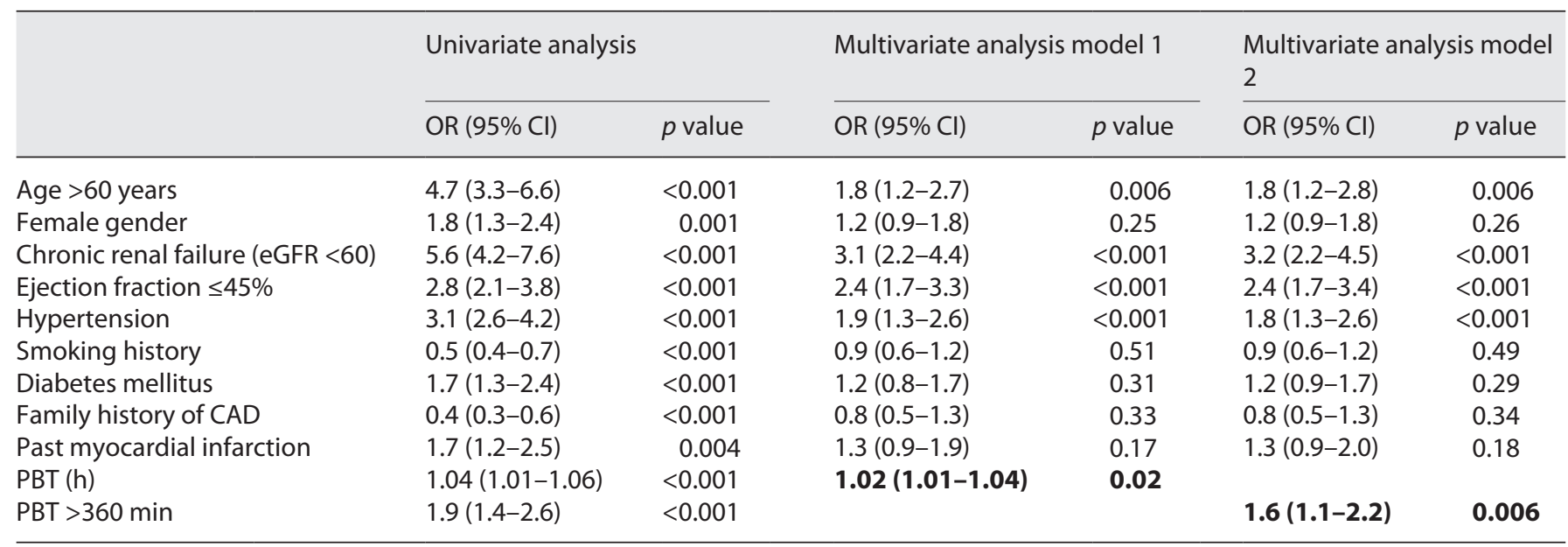

PBT, pain-to-balloon time, OR, odds ratio; $\mathrm{Cl}$, confidence interval; eGFR, estimated glomerular filtration rate; CAD, coronary artery disease. 
acute reduction of cardiac output [5] This early hemodynamic deterioration may lead to reduced renal perfusion. Bradycardia or tachycardia in the acute STEMI setting can have similar hemodynamic effects. Following the resumption of coronary flow and the graded improvement of LV function, hemodynamic impairment often resolves[5]. Indeed, patients with longer PBT demonstrated worse LV function, previously shown to be associated with AKI occurrence [19].

Short renal hypoperfusion is often associated with a prerenal failure, with transient loss of renal function without structural damage [20]. More profound and prolonged hypoperfusion primarily affects both function and structure of renal tubular epithelial cells, which, in severe cases, is characterized by epithelial-cell ischemia and necrosis. Indeed, in the present study, patients having longer PTB demonstrated graded increase in NGAL levels, an early marker of renal tubular structural damage even in the absence of functional AKI [21]. Nevertheless, ischemia-related injury may not only exclusively result in alterations of epithelial-cell function and structure but also causes interstitial inflammation and microvasculopathy, increasing susceptibility to contrast-induced AKI [9-11]. Furthermore, these alterations can result in irreversible loss or delayed restoration of renal function and progression to acute kidney disease or CKD [11]. In addition, we recently demonstrated that longer symptom duration is associated with higher admission C-reactive protein and a lower hemoglobin level in STEMI patients [22]. Thus, it appears that longer PBT results in a more pronounced inflammatory response, which may further contribute to renal damage.

Delay in seeking care after the onset of symptoms among patients undergoing primary PCI is still a vexing problem. Our findings suggest that in addition to the well-known fact that "time is myocardium" among STEMI patients, it seems that "time is kidney," with patients having longer symptom duration being more susceptible to AKI occurrence. Furthermore, novel biomarkers levels (collected within $24 \mathrm{~h}$ following admission) may offer the opportunity to detect early tubular injury even prior to actual loss of renal function (manifested as $\mathrm{sCr}$ elevation) and therefore allow early interventions for renal protection and more frequent monitoring of the urinary output $[23,24]$.

We acknowledge several important limitations of our study. This was a single-center retrospective and nonrandomized observational study and may have been subject to bias, even though we attempted to adjust for confounding factors using a multivariate regression model. No in- formation was present on concomitant medications patients were receiving; thus, their possible relation to the precipitation of AKI could have not been assessed. Although AKI definition refers to a sCr increase compared to the baseline value, the $\mathrm{sCr}$ at hospital admission may not represent a true baseline value in STEMI patients as an increase could have already occurred prior to hospital arrival, owing to the hemodynamic impairment. As access to patients' laboratory results prior to hospitalization was limited, the true baseline renal function was not known, and we referred only to values at hospital presentation as reference values for deterioration of renal function and the possible presence of CKD. Finally, the definition of AKI refers to $\mathrm{sCr}$ change within a time frame of 48 $\mathrm{h}$. As the change in $\mathrm{sCr}$ can lag beyond this time period due to delayed effects of contrast material and drugs, worsening of renal function might have occurred following hospital discharge in some patients; thus, the true incidence of AKI described in our study may have been an underestimation.

\section{Conclusion}

Among STEMI patients, PBT may be an independent marker for functional renal deterioration resulting in AKI.

\section{Statement of Ethics}

The research was conducted ethically in accordance with the World Medical Association Declaration of Helsinki. The study protocol was approved by the Local Institutional Ethics Committee (Institutional Board Review num: TLV-16-0224). Written consent was obtained from all individual participants included in the study.

\section{Conflict of Interest Statement}

The authors have no conflicts of interest to declare.

\section{Funding Sources}

No funding was received. 


\section{Author Contributions}

Keren-Lee Rozenfeld, David Zhaler, and Tamar Itach conceived the presented idea. Keren-Lee Rozenfeld, Lior Lupu, and David Zhaler developed the theory and performed the computations. Shmuel Banai and Yacov Shacham verified the analytical methods. Yacov Shacham supervised the findings of this work. Shmuel Banai reviewed and commented on the revised manuscript. All the authors discussed the results and contributed to the final manuscript.

\section{Data Availability Statement}

Based on the Local Institutional Ethical Committee, research data are not publicly available on ethical grounds. Inquiries regarding data generated or analyzed during this study can be directed to the corresponding author.

\section{References}

1 James MT, Samuel SM, Manning MA, Tonelli M, Ghali WA, Faris P, et al. Contrast-induced acute kidney injury and risk of adverse clinical outcomes after coronary angiography: a systematic review and meta-analysis. Circ Cardiovasc Interv. 2013;6:37-43.

2 Gurm HS, Dixon SR, Smith DE, Share D, Lalonde T, Greenbaum A, et al. Renal function-based contrast dosing to define safe limits of radiographic contrast media in patients undergoing percutaneous coronary interventions. J Am Coll Cardiol. 2011;58:907-14.

3 Seeliger E, Sendeski M, Rihal CS, Persson PB. Contrast-induced kidney injury: mechanisms, risk factors, and prevention. Eur Heart J. 2012;33:2007-15.

4 Shacham Y, Leshem-Rubinow E, Gal-Oz A, Arbel Y, Keren G, Roth A, et al. Acute cardiorenal syndrome as a cause for renal deterioration among myocardial infarction patients treated with primary percutaneous intervention. Can J Cardiol. 2015;31:1240-4.

5 Shacham Y, Steinvil A, Arbel Y. Acute kidney injury among ST elevation myocardial infarction patients treated by primary percutaneous coronary intervention: a multifactorial entity. J Nephrol. 2016;29:169-74.

6 Newby LK, Rutsch WR, Califf RM, Simoons ML, Aylward PE, Armstrong PW, et al. Time from symptom onset to treatment and outcomes after thrombolytic therapy. GUSTO-1 investigators. J Am Coll Cardiol. 1996;27: 1646-55.

7 Cannon CP, Gibson CM, Lambrew CT, Shoultz DA, Levy D, French WJ, et al. Relationship of symptom-onset-to-balloon time and door-to-balloon time with mortality in patients undergoing angioplasty for acute myocardial infarction. JAMA. 2000;283: 2941-7.

8 Bradley EH, Nallamothu BK, Herrin J, Ting $\mathrm{HH}$, Stern AF, Nembhard IM, et al. National efforts to improve door-to-balloon time results from the door-to-balloon alliance. J Am Coll Cardiol. 2009;54:2423-9.
9 Chertow GM, Burdick E, Honour M, Bonventre JV, Bates DW. Acute kidney injury, mortality, length of stay, and costs in hospitalized patients. J Am Soc Nephrol. 2005;16:3365-70.

10 Lameire N, Van Biesen W, Vanholder R. Acute renal failure. Lancet. 2005;365:417-30.

11 Schrier RW, Wang W, Poole B, Mitra A. Acute renal failure: definitions, diagnosis, pathogenesis, and therapy. J Clin Invest. 2004; 114:5-14.

12 Shacham Y, Leshem-Rubinow E, Gal-Oz A, Arbel Y, Keren G, Roth A, et al. Relation of time to coronary reperfusion and the development of acute kidney injury after ST-segment elevation myocardial infarction. Am J Cardiol. 2014;114:1131-5.

13 Ibanez B, James S, Agewall S, Antunes MJ, Bucciarelli-Ducci C, Bueno H, et al. 2017 ESC guidelines for the management of acute myocardial infarction in patients presenting with ST-segment elevation: the task force for the management of acute myocardial infarction in patients presenting with ST-segment elevation of the European Society of Cardiology (ESC). Eur Heart J. 2018;39:119-77.

14 Levey AS, Stevens LA, Schmid CH, Zhang YL, Castro AF 3rd, Feldman HI, et al. A new equation to estimate glomerular filtration rate. Ann Intern Med. 2009;150:604-12.

15 Stevens PE, Levin A; Kidney Disease: Improving Global Outcomes Chronic Kidney Disease Guideline Development Work Group Members. Evaluation and management of chronic kidney disease: synopsis of the kidney disease - improving global outcomes 2012 clinical practice guideline. Ann Intern Med. 2013;158:825-30.

16 Krumholz HM, Bradley EH, Nallamothu BK, Ting HH, Batchelor WB, Kline-Rogers E, et al. A campaign to improve the timeliness of primary percutaneous coronary intervention: door-to-balloon - an alliance for quality. JACC Cardiovasc Interv. 2008;1:97-104.
17 De Luca G, Suryapranata H, Zijlstra F, van 't Hof AW, Hoorntje JC, Gosselink AT, et al. Symptom-onset-to-balloon time and mortality in patients with acute myocardial infarction treated by primary angioplasty. J Am Coll Cardiol. 2003;42:991-7.

18 Shiomi H, Nakagawa Y, Morimoto T, Furukawa Y, Nakano A, Shirai S, et al. Association of onset to balloon and door to balloon time with long term clinical outcome in patients with ST elevation acute myocardial infarction having primary percutaneous coronary intervention: observational study. BMJ. 2012;344: e3257.

19 Shacham Y, Leshem-Rubinow E, Gal-Oz A, Topilsky Y, Steinvil A, Keren G, et al. Association of left ventricular function and acute kidney injury among ST-elevation myocardial infarction patients treated by primary percutaneous intervention. Am J Cardiol. 2015;115:293-7.

20 Devarajan P. Update on mechanisms of ischemic acute kidney injury. J Am Soc Nephrol. 2006;17:1503-20

21 Rozenfeld KL, Zahler D, Shtark M, Goldiner I, Keren G, Banai S, et al. Elevated neutrophil gelatinase-associated lipocalin for the assessment of structural versus functional renal damage among ST-segment elevation myocardial infarction patients. Blood Purif. 2020; 49(5):560-6.

22 Shacham Y, Leshem-Rubinow E, Ben-Assa E, Roth A, Steinvil A. Lower admission hemoglobin levels are associated with longer symptom duration in acute ST-elevation myocardial infarction. Clin Cardiol. 2014;37:73-7.

23 Coca SG, Yalavarthy R, Concato J, Parikh CR. Biomarkers for the diagnosis and risk stratification of acute kidney injury: a systematic review. Kidney Int. 2008;73:1008-16.

24 Koyner JL, Parikh CR. Clinical utility of biomarkers of AKI in cardiac surgery and critical illness. Clin J Am Soc Nephrol. 2013;8:103442. 